\title{
A young man with acute dilated cardiomyopathy associated with methylphenidate
}

\author{
Tor-Bjarne Nymark' \\ A Hovland ${ }^{2}$ \\ H Bjørnstad ${ }^{2}$ \\ E W Nielsen ${ }^{1,3}$
}

'Section for Emergency Medicine; ${ }^{2}$ Department of Cardiology, Nordland Hospital, Bodø, Norway; ${ }^{3}$ University of Tromsø, Tromsø, Norway
Correspondence:Tor-Bjarne Nymark Section for Emergency Medicine, Nordland Hospital, 8092 Bodø, Norway Tel +4775534000

Email tor.bjarne.nymark@nlsh.no

\begin{abstract}
An 18-year-old obese man with a body mass index of 40, diagnosed with attention-deficit hyperactivity disorder and treated with methylphenidate (Concerta ${ }^{\circledR}$ ) was acutely admitted to hospital with hypoxia and dyspnoea. On investigation signs of liver-, renal-, and heart-failure were found. Noradrenalin infusion was started. Echocardiography showed dilated left ventricle and an ejection fraction (EF) of 25\%. Liver function improved, noradrenalin and dobutamine were tapered, but three days after admission a new echocardiography showed an EF of $10 \%$. The patient was transferred to the National Hospital (Rikshospitalet, Oslo), where intensified treatment including intra aortic balloon pump (IABP) was instituted. Cardiac function improved, and 3 weeks later the IABP was disconnected. EF at this point was $15 \%$. The patient was denied heart transplantation due to various cofactors. The investigation concluded with a probable relationship between his cardiomyopathy and the use of methylphenidate (Concerta). Keywords: cardiomyopathy, heart failure, ADHD, methylphenidate
\end{abstract}

Heart failure due to idiopathic dilated cardiomyopathy (DCM) is rare in young people. Familial linkage is often found (Seidman and Seidman 2001), and various drugs, especially cytotoxic drugs, may cause cardiomyopathy (Giordano et al 2002). Cocaine and amphetamines are known to have caused DCM (Lange and Hillis 2001). There are very few reports linking methylphenidate therapy to DCM, but recently the Journal of the Norwegian Medical Association described how a young boy treated with methylphenidate died of dilated cardiomyopathy (Tollofsrud and Hoel 2006). We report a similar case but with a different outcome.

\section{Case description}

An 18-year-old male was diagnosed with attention-deficit hyperactivity disorder (ADHD) in 2005. He was overweight with a body mass index (BMI) of 40. He was started on quetiapine fumarate (Seroquel ${ }^{\circledR}$ ) $900 \mathrm{mg}$ daily in April 2005 and methylphenidate $\left(\right.$ Concerta $\left.^{\circledR}\right) 54 \mathrm{mg}$ daily in September 2005. In the beginning of August 2006 he was admitted to his local hospital with severe dyspnoea, tachypnea, tachycardia, and cyanosis. On admission the blood pressure was $120 / 80 \mathrm{mmHg}$, and the arterial blood gas revealed a $\mathrm{pH}$ of $7.45, \mathrm{pCO} 2$ of $3.55 \mathrm{kPa}, \mathrm{paO} 2$ of $7.76 \mathrm{kPa}$, and $\mathrm{BE}$ of -5.1 $\mathrm{mmol} / \mathrm{l}$. C-reactive protein was not elevated. The chest X-ray showed an enlarged heart. He developed hemoptysis and was treated with unfractionated heparin in suspicion of pulmonary embolism. He subsequently developed cardiogenic shock and was treated with vasoactive drugs. In spite of the treatment he became oliguric and his liver enzymes were rising. He was referred to our hospital for further treatment. On admission the blood pressure was $90 / 60 \mathrm{mmHg}$, despite infusion with noradrenaline. His heart rate was $130 /$ minute and his temperature was $38.4^{\circ} \mathrm{C}$. A thoracic computed tomography scan did not show pulmonary embolism. Echocardiography revealed biventricular 
failure and left ventricular end diastolic diameter was $7 \mathrm{~cm}$. The left ventricle was severely hypokinetic with an ejection fraction (EF) of 20\%-25\%. The left ventricular end diastolic pressure was markedly elevated, and there was a moderate mitral regurgitation. Intermittent hemodialysis was initiated. His liver function improved slightly, but despite dialysis the renal function deteriorated with increasing creatinine values. After three days there was a further worsening of the left ventricular systolic function with an ejection fraction of $10 \%-12 \%$ and marked pulmonary hypertension with systolic pulmonary pressure estimated to $30 \mathrm{mmHg}$. The clinical picture resembled dilated cardiomyopathy with low output failure causing renal and liver failure. We suspected drug-induced cardiomyopathy and methylphenidate and quetiapine fumarate were discontinued. Screening for infectious pathogens, immunological markers, and iron or amyloid deposition were all negative. After three days he was transferred to the National Hospital (Rikshospitalet, Oslo) with ongoing noradrenaline and dobutamine infusions. Shortly after admission an intraaortic balloon pump (IABP) was inserted and noradrenaline was replaced by nitroprusside. Coronary angiography was normal. Endomyocardial biopsy from the right ventricle did not reveal any distinct myocardial pathology. On treatment with IABP, nitroprusside, and dialysis, the clinical situation gradually improved and the liver function returned to normal. His renal function also improved with increasing diuresis and creatinine fell from 798 to 98 $\mu \mathrm{mol} / 1$. His EF was still markedly reduced (15\%). Because of behavioral problems and adipose stature, he was denied a heart transplant. He was treated with IABP for 26 days, and after 28 days he was transferred back to our hospital. At that time his liver and renal functions were normal. He was treated with an angiotensin-converting enzyme (ACE)-inhibitor, a beta-blocker, and diuretics. During the following two weeks his clinical status improved and he was subsequently discharged to his home. The echocardiography still showed markedly dilated left ventricle with EF of $20 \%$.

In March 2007, his clinical status was improved and he was in function class II (New York Heart Association) with an EF estimated by echocardiography to $30 \%-35 \%$.

\section{Discussion}

Our patient presented with progressive cardiac failure leading to liver and renal failure. Previously he was diagnosed with ADHD and was treated with methylphenidate and quetiapine fumarate. The Journal of the Norwegian Medical Association recently presented a case describing a 17-year-old boy who died from dilated cardiomyopathy. Treatment with methylphenidate (Ritalin ${ }^{\circledR}$ ) for 10 years was suspected to be the cause (Tollofsrud and Hoel 2006).

Cardiac adverse effects from methylphenidate have been shown to affect myocardial ultra-structure in rats. This effect was irreversible after 12 weeks (Henderson and Fischer 1995). Methylphenidate is a drug with central nervous stimulating action and with similar effects as amphetamines. Both increase synaptic and intracellular dopamine in rodents and baboons (Schiffer et al 2006). For amphetamine the mechanism has been shown to be both increased release of catecholamines and a blockade of their synaptic reuptake and degradation (Knepper et al 1988). It is the increase in adrenergic action that is believed to be cardiotoxic over time and promote cardiomyopathy (Lange and Hillis 2001). Thus, in transgenic mice, myocardial overexpression of beta-adrenergic receptors was associated with myocyte apoptosis and the development of dilated cardiomyopathy (Singh et al 2001).

With a BMI of 40 our patient had extreme obesity. The hyperdynamic circulation, with increased cardiac output, thought to be a compensatory adaptation to increased adipose tissue may, at the expense of left ventricular hypertrophy and remodeling, lead to nonischemic dilated cardiomyopathy in severe obese subjects (McGavock et al 2006). This is, however, unlikely as the only cause in our young patient. Human obesity is also characterized by sympathetic nervous activation (Eikelis and Esler 2005). A possible obesity-linked susceptibility to the toxic effect of methylphenidate could therefore play a role in the development of DCM in our patient, especially with regards to the short treatment time of one year. In comparison, the previously reported patient had been treated with the same drug for 10 years (Tollofsrud and Hoel 2006).

There is one report of myocarditis associated with quetiapine (Roesch-Ely 2002), and our patient had been treated with quetiapine for 17 months when he was admitted to our hospital. This drug could therefore also play a role in the development of DCM. There was, however, no signs of myocarditis or any other distinct pathology on myocardial biopsy.

In February 2006, an advisory committee to the U.S. Food and Drug Administration (FDA) urged the most serious FDA warning, the "black box", be placed on all drugs prescribed to treat ADHD (Nissen 2006). The concern, however, was not restricted to cardiomyopathy alone, but to various cardiovascular side effects. After this report, the Norwegian and European Medicines Agency also pay close attention to reports on cardiovascular side effects of these drugs (Madsen 2006). 


\section{Conclusion}

We report the second case in a short time in Norway of serious cardiomyopathy in young patients treated with methylphenidate. The concern is that methylphenidate is the responsible agent. Although the number treated with this drug is high, and the reported cardiovascular side effects are few, we are concerned about the serious infliction this side effect could have on children and young adults. To our knowledge, there are no guidelines regarding how to identify individuals prone to develop cardiomyopathy due to central stimulating drugs. Further studies addressing this problem need to be done.

\section{References}

Eikelis N, Esler M. 2005. The neurobiology of human obesity. Exp Physiol, 90:673-82.

Giordano SH, Booser DJ, Murray JL, et al. 2002. A detailed evaluation of cardiac toxicity: a phase II study of doxorubicin and one- or threehour-infusion paclitaxel in patients with metastatic breast cancer. Clin Cancer Res, 8:3360-8.
Henderson TA, Fischer VW. 1995. Effects of methylphenidate (Ritalin) on mammalian myocardial ultrastructure. Am J Cardiovasc Pathol, 5:68-78.

Knepper SM, Grunewald GL, Rutledge CO. 1988. Inhibition of norepinephrine transport into synaptic vesicles by amphetamine analogs. $J$ Pharmacol Exp Ther, 247:487-94.

Lange RA, Hillis LD. 2001. Cardiovascular complications of cocaine use. N Engl J Med, 345:351-8.

Madsen S. 2006. Legemidler mot ADHD og risiko for hjertesykdom [online]. Norwegian Medicines Agency. Accessed on Nov 4, 2007. URL: http:// www.slk.no/templates/InterPage__30193.aspx.

McGavock JM, Victor RG, Unger RH, et al. 2006. Adiposity of the Heart*, Revisited. Ann Intern Med, 144:517-24.

Nissen SE. 2006. ADHD drugs and cardiovascular risk. $N$ Engl J Med, 354:1445-8.

Schiffer WK, Volkow ND, Fowler JS, et al. 2006. Therapeutic doses of amphetamine or methylphenidate differentially increase synaptic and extracellular dopamine. Synapse, 59:243-51.

Seidman JG, Seidman C. 2001. The genetic basis for cardiomyopathy: from mutation identification to mechanistic paradigms. Cell, 104:557-67.

Singh K, Xiao L, Remondino A, et al. 2001. Adrenergic regulation of cardiac myocyte apoptosis. J Cell Physiol, 189:257-65.

Tollofsrud C, Hoel T. 2006. [A young man with acute dilated cardiomyopathy]. Tidsskr Nor Laegeforen, 126:1338-9. 